\title{
Adsorption Study of Rhodamine B and Methylene Blue Dyes with ZSM-5 Directly Synthesized from Bangka Kaolin without Organic Template
}

\author{
Ani Iryani ${ }^{1,2}$, Hadi Nur ${ }^{3}$, Mardi Santoso ${ }^{2}$, and Djoko Hartanto ${ }^{2, *}$ \\ ${ }^{1}$ Department of Chemistry, Faculty of Mathematics and Natural Sciences, Universitas Pakuan, \\ Jl. Pakuan, Tegallega, Bogor 16143, Indonesia \\ ${ }^{2}$ Department of Chemistry, Faculty of Sciences, Institut Teknologi Sepuluh Nopember, Keputih, Surabaya 60111, Indonesia \\ ${ }^{3}$ Ibnu Sina Institute for Scientific and Industrial Research, Universiti Teknologi Malaysia, Johor, Malaysia
}

* Corresponding author:

email: djokohar@its.ac.id

Received: November 27, 2018

Accepted: March 8, 2019

DOI: $10.22146 /$ ijc.41369

\begin{abstract}
Rhodamine $B(R B)$ and Methylene Blue $(M B)$ dyes adsorption using adsorbent ZSM-5 synthesized from Bangka kaolin were investigated in this study. The effects of the initial concentration, contact time, and temperature on the adsorption process were also analyzed. The effect of the initial concentration and contact time played an important role in the adsorption process; however, the effect differs significantly in both dyes. The temperature plays little role in the dye adsorption process. The results showed that the adsorption process occurred in ZSM-5 adhere to Langmuir isothermal adsorption model showing that the adsorption process occurred to be monolayer. Based on the kinetics studies, the pseudo-first-order kinetic model represents the adsorption kinetics that occurs for both dyes onto the synthesized ZSM-5. Thermodynamic parameters namely Gibbs free energy $\left(\Delta G^{\circ}\right)$, standard entropy changes $\left(\Delta S^{\circ}\right)$ and standard enthalpy $\left(\Delta H^{\circ}\right)$ reveal that the adsorption process onto ZSM-5 for both dyes was spontaneous and exothermic.
\end{abstract}

Keywords: Bangka kaolin; dyes; isotherm adsorption; kinetics; thermodynamics; ZSM-5

\section{- INTRODUCTION}

The presence of dye effluent on the environment has become a major world problem due to their damaging effects on aquatic life and ecosystem [1]. Discharge of dye effluent also has a great health threat to all forms of life as a dye is either toxic or mutagenic and also carcinogenic compounds [2]. On water bodies, dye effluent leads the changes in water color, which reduce light penetration and inhibit photosynthesis of aqueous organism and flora. Moreover, the dye is not only highly soluble and stable in water, but also not easily degraded in the aqueous system that makes removal efforts complicated and arduous [3]. Rhodamine B (RB) and Methylene Blue (MB) are two cationic dyes that commonly used as dyes in the textile industry for cotton, leather, and wool coloration. These dyes come from thiazine and xanthate class, respectively, which also used in the cosmetics and pharmaceutical industry [4-5]. RB and MB are known to be carcinogenic, mutagenic, and poisonous to animal and human life. Also, it is nonbiodegradable and persists into the environment at high concentration [6-7]. Thus, the treatment of colored effluents before discharge as wastewater become a major concern.

Several processes had been developed by experts to solve this problem such as sonochemical degradation [8], photochemistry [9], electrochemistry [10], membrane separation [11], adsorption [12] oxidation or ozonation [13]. From the mentioned methods, the adsorption process has attracted the attention of researchers because of its advantages in terms of flexibility, cost, and simplicity. The adsorption process was proven as an effective method to remove metal ions in water. Interestingly, the adsorption process is also commercially efficient, versatile and feasible to remove textile dyes from wastewater [14].

Several studies have been performed on dyes 
adsorption to investigate the factors that affect adsorption performance including isotherm models, kinetics, and thermodynamic studies. Many adsorbents were studied on their performance to remove dyes from wastewater, including bamboo dust, coconut shell, bagasse, and activated carbon [15]. However, the high cost of treatment and activation limit the usage of these adsorbents. This is the reason why researchers have to study the feasibility of using cheap and commercially available materials with large pore-space and special surface property such as clay-based material like MCM41 and zeolites [16]. Zeolites are a series of microporous aluminosilicate crystal with interconnected pores and channels in size range from 0.3 to $1 \mathrm{~nm}$. Their threedimensional framework facilitates the adsorption of an organic molecule into its channel [17].

ZSM-5 is a type of zeolite that very potential to be developed as an adsorbent for an organic molecule. This material is usually prepared using an organic template or well known as organic structure-directing agent (OSDA) template to alter the formation of pores in their particles. However, the usage of OSDA templates, for example tetrapropylammonium [18], cetyl trimethylammonium bromide (CTAB) [19], organosilane compounds [14,18] or carboxymethyl cellulose (CMC) [20], during the ZSM5 synthesis implies the increase in the production costs and air pollution due to thermal decomposition of this OSDA. Moreover, a tedious step must be employed to prepare ZSM-5 from this method [21]. In addition, the ZSM-5 is usually synthesized using fine chemicals such as sodium aluminate $\left(\mathrm{NaAlO}_{2}\right)$ as an alumina source and Ludox or TEOS as a silica source. In this works, kaolin Bangka was used as an alumina source. Kaolin is an aluminosilicate clay mineral that consists of alumina and silica with a ratio of $1: 1$. The relatively high alumina content in kaolin Bangka can reduce the use of expensive and less environmentally-friendly chemicals [22]. Thus, it is expected to reduce the production cost as well as the environmental impact of ZSM-5 synthesis.

The adsorption of $\mathrm{RB}$ and $\mathrm{MB}$, indeed, have been reported by several researchers. Damiyine et al. reported the usage of clay to adsorb RB, and the result suggested that the adsorption process preferably at higher $\mathrm{pH}$ with the adsorption capacity of the material reached $89.28 \mathrm{mg} / \mathrm{g}$ of RB [23]. Turning to MB, Ngapa et al. reported adsorption of $\mathrm{MB}$ using natural zeolite (Mordenite) from Ende [24]. It was found that the modification of natural zeolites could significantly increase the adsorption of MB. The unmodified natural zeolite could only adsorb as much as $16-17 \mathrm{mg} / \mathrm{g}$ of $\mathrm{MB}$, and this number increase twofold (reaching $36-37 \mathrm{mg} / \mathrm{g}$ ) after modification using the hydrothermal process [24]. Vezentsev et al. also reported adsorption of MB using bentonite clay and hydroxyapatite, and it was found that bentonite clay could adsorb MB significantly higher than hydroxyapatite. The adsorption using Bentonite was $175.4 \mathrm{mg} / \mathrm{g}, 17.8$ times higher than hydroxyapatite ones. [25]. Lately, Santosa et al. adsorb MB using peat soil humin. They revealed that this material could adsorp the MB up to $60.77 \mathrm{mg} / \mathrm{g}$. Despite these reports, the adsorption of this dye should still be improved to reach the practical application [26]. In this case, the adsorption process using ZSM-5 synthesized of kaolin Bangka as starting material and without organic template has not been reported yet. The usage of different starting material and different synthesis route compare to conventional ZSM-5 synthesis could lead to the formation of a specific characteristic of the yielded ZSM-5 powders. Therefore, the adsorption of RB and MB dyes on ZSM-5 synthesized using kaolin Bangka and without organic template was investigated in this study to understand the effectiveness of this ZSM-5 and its characteristic in adsorption of both dyes. The characteristics of the ZSM-5 were characterized by Fourier transform infrared spectroscopy (FTIR), X-ray diffraction (XRD), $\mathrm{N}_{2}$-sorption (BET and BJH methods), and scanning electron microscopy (SEM). Then, the ability of ZSM-5 as adsorbents to adsorb RB and MB dyes from aqueous media was evaluated.

\section{- EXPERIMENTAL SECTION}

\section{Materials}

ZSM-5, in this work, was synthesized from Bangka kaolin without pre-treatment nor without using organic (OSDA) template. The synthesis process was adopted from previous work taking the $\mathrm{Si} / \mathrm{Al}$ molar ratio of 60 
[27]. Two types of dyes materials were used as adsorbate in this experiment which are $\mathrm{RB}$ and $\mathrm{MB}$. $\mathrm{RB}$ has a chemical formula of $\mathrm{C}_{28} \mathrm{H}_{31} \mathrm{ClN}_{2} \mathrm{O}_{3}$ and molecular weight of $479.02 \mathrm{~g} / \mathrm{mol}$, melting point $210-211^{\circ} \mathrm{C}$ and $\lambda_{\max } 355$ and $543 \mathrm{~nm}$, whereas $\mathrm{MB}$ has a chemical formula of $\mathrm{C}_{16} \mathrm{H}_{18} \mathrm{ClN}_{3} \mathrm{~S}$ and molecular weight of $319.85 \mathrm{~g} / \mathrm{mol}$, a melting point between $100-110^{\circ} \mathrm{C}$ and $\lambda_{\max } 665 \mathrm{~nm}$.

\section{Procedure}

\section{Synthesis procedure}

ZSM-5 was synthesized from kaolin directly without the addition of organic (OSDA) template. The synthesis was started by dividing $16.59 \mathrm{~g}$ of aqua DI into two parts. Then, $0.8 \mathrm{~g}$ of $\mathrm{NaOH}$ was dissolved into the first half of the aqua DI followed by addition $0.93 \mathrm{~g}$ of kaolin under constant stirring. Subsequently, $22.58 \mathrm{~g}$ of Ludox was added to the mixture step by step. The second half of water was added to the mixture to give a final ratio of $10 \mathrm{Na}_{2} \mathrm{O}: 120 \mathrm{SiO}_{2}: 2 \mathrm{Al}_{2} \mathrm{O}_{3}: 1800 \mathrm{H}_{2} \mathrm{O}$. This mixture was then aged at room temperature for $12 \mathrm{~h}$. The silicalite- 1 seed was then added to the mixture and continued by constant stirring for $30 \mathrm{~min}$. The mixture was then moved into stainless-steel Teflon autoclave for a hydrothermal process. The hydrothermal process was performed under a closed condition at $448 \mathrm{~K}$ for $24 \mathrm{~h}$. The resulted powders were separated by centrifugation $(5000 \mathrm{rpm})$ and washed with aqua DI until reaching neutral $\mathrm{pH}$ and were then dried at $373 \mathrm{~K}$ for $12 \mathrm{~h}$. This process produced Na-ZSM5. The resulted powders were calcined at $773 \mathrm{~K}$ under air atmosphere. After calcination, $1 \mathrm{~g}$ of Na-ZSM-5 was placed into $20 \mathrm{~mL}$ ammonium chloride solution $0.6 \mathrm{M}$. The mixture was then stirred for $1 \mathrm{~h}$. The powders were then filtered and were washed using aqua DI to reach neutral $\mathrm{pH}(\mathrm{pH}=6-7)$. The resulted powders were dried and were calcined at $773 \mathrm{~K}$ for $6 \mathrm{~h}$. This process resulted in H-ZSM- 5 or mentioned as ZSM-5.

\section{Characterization of ZSM-5}

The synthesized ZSM-5 was characterized using Xray diffraction (XRD) by powder technique and with CuKa irradiation $(\lambda=1.54 \AA)$ at $2 \theta$ range of $5-40^{\circ}$. The textural properties of the sample were characterized by Nitrogen adsorption at $77 \mathrm{~K}$ on Micromeritics ASAP 2020 instrument. Prior to sorption measurements, the samples are placed into the $\mathrm{U}$-shaped tube at $400{ }^{\circ} \mathrm{C}$ for $8 \mathrm{~h}$ for degassing. The determination of the total surface area was based on the Brunauer-Emmett-Teller (BET) adsorption isotherm model. Meanwhile, the BarrettJoyner-Halenda (BJH) is used to calculate the pore size distribution and the pore volume. Scanning electron microscopy (SEM) was conducted to examine the particle morphology of the zeolite particles. This analysis was conducted using a Zeiss EVO MA at $20 \mathrm{kV}$. The infrared Spectroscopy was carried out using Fourier Transform Infrared (FTIR) Shimadzu Spectrum One 8400 S to analyze function group of the synthesized material.

\section{Adsorption procedure}

Adsorption of RB and $\mathrm{MB}$ dyes were conducted by the batch method. The experiment procedure conducted on a container that filled with $50 \mathrm{~mL}$ dyes solution (both $\mathrm{RB}$ and $\mathrm{MB}$ ) with variation concentration of 50,100 , 150,200 and $250 \mathrm{mg} / \mathrm{L}$ for each dye. The initial $\mathrm{pH}$ of the solution is 7, and the amount of adsorbent (ZSM-5) is $0.05 \mathrm{~g}$. The tube was then stirred at a determined temperature until equilibrium is reached. Upon equilibrium, the solution then filtered through $0.1 \mu \mathrm{m}$ of membrane filter (Millipore, Japan) and the absorption were measured at maximum absorbance of dyes with UV-Visible Spectrophotometer (Thermo GeneSYS 10S) to determine the residual of dye concentration. The adsorption capacity was calculated by Eq. (1):

$\mathrm{Q}_{\mathrm{e}}=\frac{\left(\mathrm{C}_{\mathrm{o}}-\mathrm{C}_{\mathrm{e}}\right)}{\mathrm{m}} \times \mathrm{V}$

where $Q_{e}$ is the adsorption capacity per unit of adsorbent $(\mathrm{mg} / \mathrm{g}), \mathrm{C}_{\mathrm{o}}$ is the initial dye concentration $(\mathrm{mg} / \mathrm{L}), \mathrm{C}_{\mathrm{e}}$ is the residual dye concentration $(\mathrm{mg} / \mathrm{L}), \mathrm{V}$ is the volume of the solution (L) and $\mathrm{m}$ is the weight of the adsorbent (g).

The results of this study were analyzed using the isotherm adsorption model of Langmuir, Freundlich, Temkin, and Dubinin-Radushkevich (DR) [28-29]. Calculation of the isotherm adsorption model is taken from data obtained between contact time 0-180 min. The sample solution was taken every $10 \mathrm{~min}$ along contact time and directly analyzed with UV-Visible spectrophotometer. This analysis is carried out with dye 
(adsorbate) concentration of 50, 100, 150, 200 and $250 \mathrm{mg} / \mathrm{L}$. The variation temperature applied are 303, 313, and $323 \mathrm{~K}$.

\section{- RESULTS AND DISCUSSION}

ZSM-5 was successfully synthesized from Bangka kaolin using silicalite-1 seeds and without an organic template. For this synthesis process, the molar ratio of reactants is determined based on the previous study reported by Prasetyoko et al. who synthesized ZSM-5 with a molar ratio of $10 \mathrm{Na}_{2} \mathrm{O}: 120 \mathrm{SiO}_{2}: 2 \mathrm{Al}_{2} \mathrm{O}_{3}: 1800 \mathrm{H}_{2} \mathrm{O}$ [30]. However, this study uses kaolin Bangka as a source of alumina and silica.

\section{Characterization of ZSM-5}

Fig. 1 illustrated the powder XRD diffractogram of Bangka kaolin and synthesized ZSM-5. The comparison of the diffractogram shows that the specific peak of kaolin did not appear in the diffractogram of synthesized ZSM5. These results point out that kaolin phase was fully transformed into ZSM-5 after synthesis process. The main peaks of Synthesized ZSM-5 at $2 \theta=7.9,8.9,23.2$, and $24.5^{\circ}$ are identical with reference of ZSM-5, which mean that pure ZSM-5 was obtained without impurities [30]. High intensity shows that the ZSM-5 was synthesized with good crystallinity.

The FTIR spectra of kaolin and synthesized ZSM-5 can be seen in Fig. 2. The spectra show that there is great difference between Bangka kaolin and Synthesized ZSM5 , which suggest that the kaolin bond was disconnected and transformed into novel ZSM-5 bond by synthesis process. The characteristic peak of ZSM-5 at 1221 and $1102 \mathrm{~cm}^{-1}$ represent the asymmetric stretching vibration of TOT bond; peak at $796 \mathrm{~cm}^{-1}$ displays symmetric stretching vibration of T-O-T bond; $546 \mathrm{~cm}^{-1}$ shows the framework vibration of pentacyclic ring that is characteristic vibration of the MFI-type structure and peak at $450 \mathrm{~cm}^{-1}$ is a result of the bending vibration of TOT, where $\mathrm{T}$ is $\mathrm{Si}$ or $\mathrm{Al}$ atoms [31-32].

The SEM micrograph of the synthesized ZSM-5 is presented in Fig. 3. The morphology of ZSM-5 reveals the typical smooth and fine hexagonal structure with a size of about 9.6-3.3 $\mu \mathrm{m}$. However, there is some part that exhibits irregularly layered and cracked structure with a rectangular

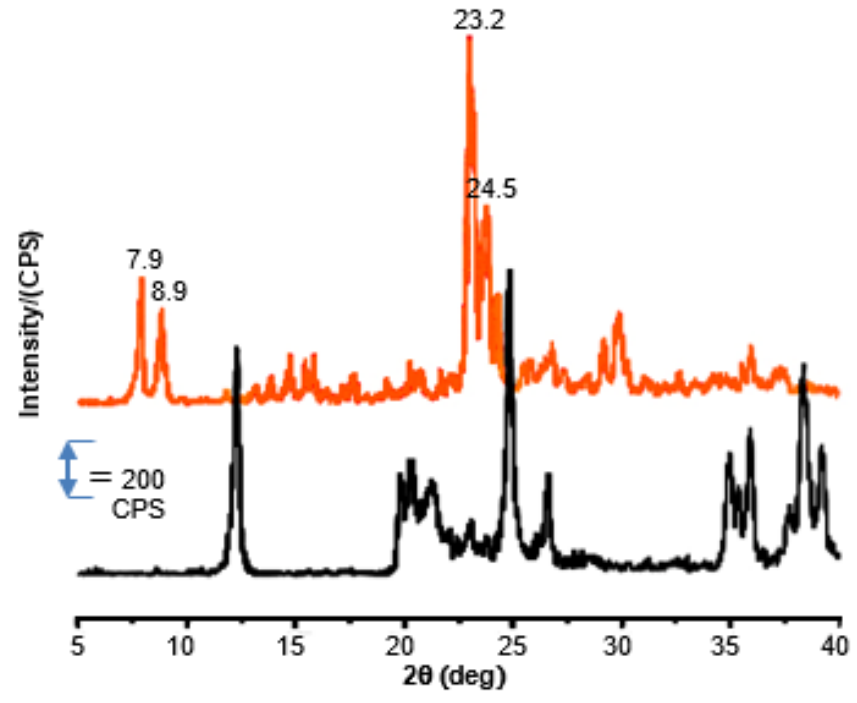

Fig 1. Diffractogram XRD of (a) Bangka kaolin and (b) synthesized ZSM-5

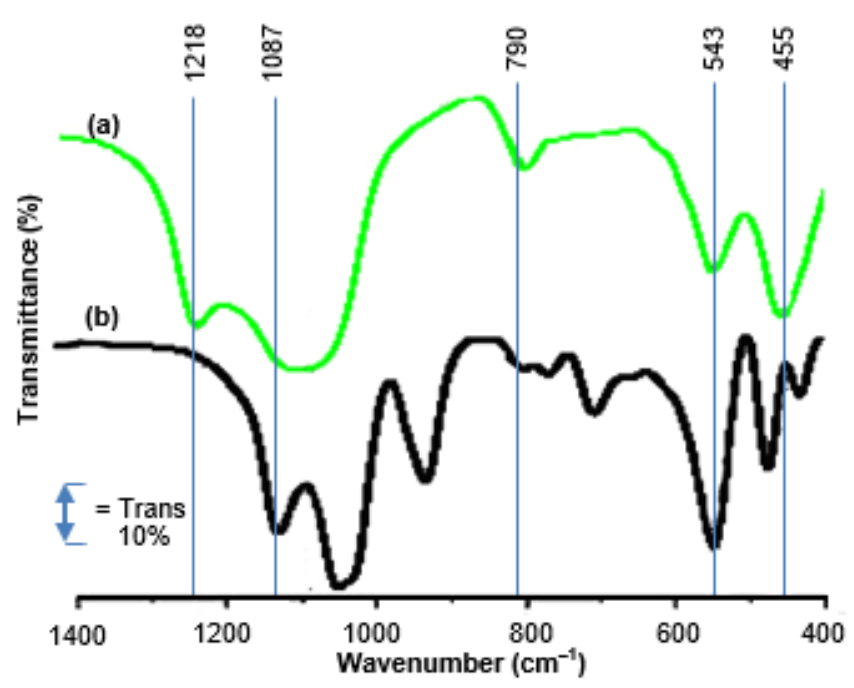

Fig 2. Infrared spectra of (a) Bangka kaolin and (b) synthesized ZSM-5

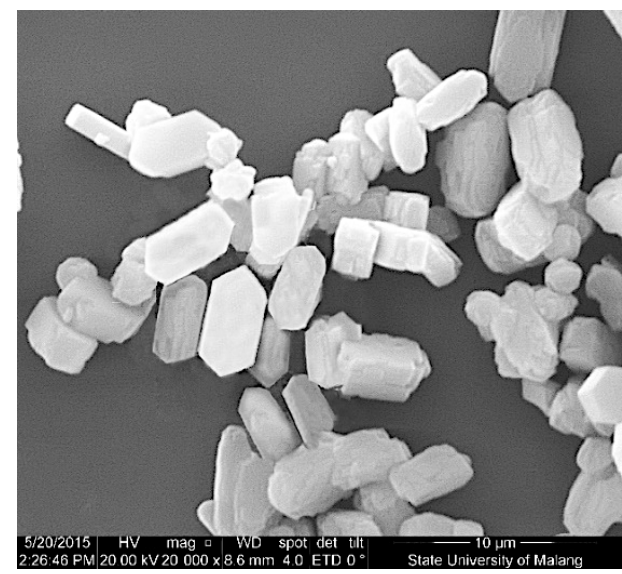

Fig 3. Micrograph SEM of synthesized ZSM-5 
shape in size of about 9.6-3.8 $\mu \mathrm{m}$.

The textural properties of synthesized ZSM- 5 were evaluated by nitrogen physisorption and can be seen in Fig. 4 . The $\mathrm{N}_{2}$ Sorption of ZSM-5 shows the significant increase of adsorption in two steps, as can be seen in the relative pressure $\left(\mathrm{P} / \mathrm{P}_{0}\right)<0.02$ and $\left(\mathrm{P} / \mathrm{P}_{0}\right)>0.95$. The first increase at $\left(\mathrm{P} / \mathrm{P}_{0}\right)<0.02$ indicates the filling of the micropore exists in the ZSM-5 surface. In contrast, the increase in a higher pressure at $\left(\mathrm{P} / \mathrm{P}_{0}\right)>0.95$ indicates the presence of interparticle void caused by aggregation of primary crystal.

The ZSM-5 also shows the hysteresis loop at $\sim 0.5<\mathrm{P} / \mathrm{P} 0<0.9$, which indicates the presence of mesopore. The relatively large hysteresis indicates the existence of interconnected open mesopore to the external surface of ZSM-5. This interconnected mesopore could improve the molecular transport due to the reducing of diffusion length to the micropore. The surface area of the sample is found to be about $333 \mathrm{~m}^{2} / \mathrm{g}$ based on BET calculation. Meanwhile, the pore diameter of ZSM-5 calculated using the BJH method was found to be $5.72 \AA$ and 24-26 ̊ [33-34].

Batch adsorption studies of $\mathrm{RB}$ and $\mathrm{MB}$ in aqueous media was performed to examine the adsorption performance of ZSM-5 from Bangka kaolin. The effect of initial concentration, contact time, and the temperature are explained detail in the following discussion.

\section{Effect of Initial Concentration and Contact Time}

The initial concentration of dye and contact time are
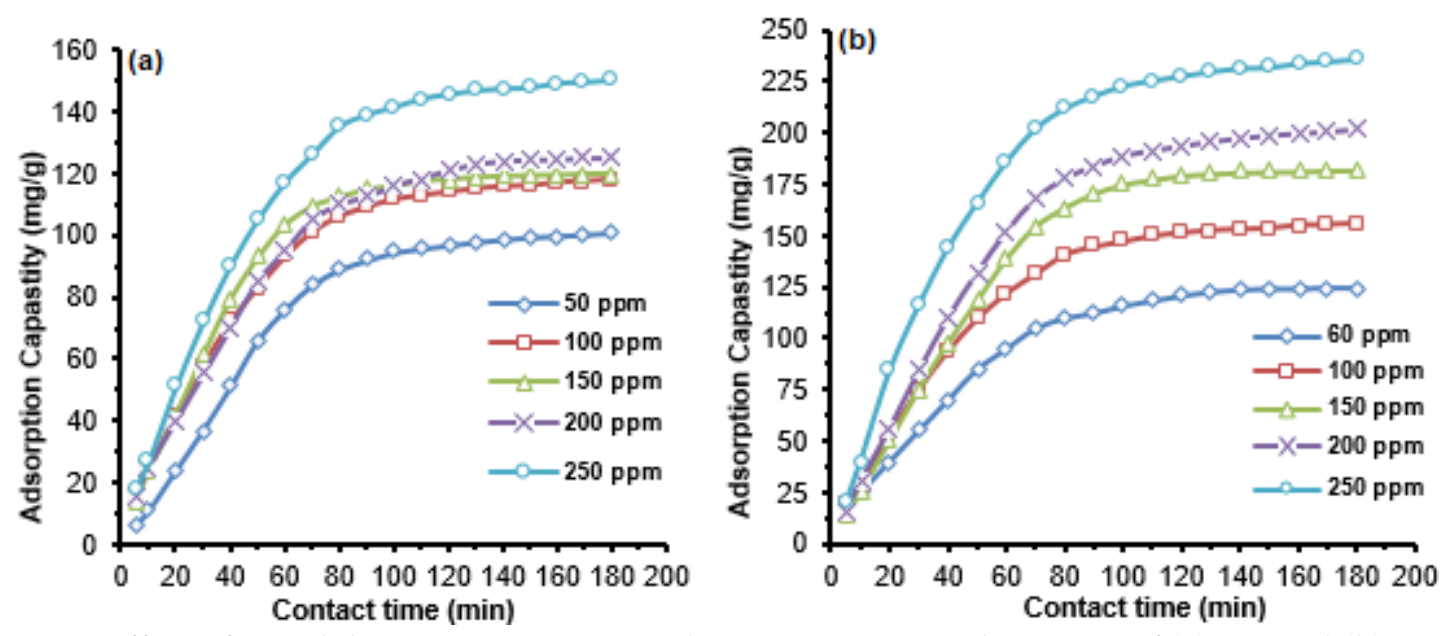

Fig 5. Effect of initial dyes concentration and contact time on adsorption of (a) RB and (b) MB two important factors influencing the adsorption process, since initial concentration can affect the driving force of dye molecules to overcome limited mass transport between solid-liquid phase boundaries. Contact time also a crucial factor in revealing equilibrium adsorption point of dye molecules [16]. The effect of initial dyes concentration and contact time on the adsorption capacity of RB and MB by ZSM-5 is illustrated in Fig. 5. The curve in Fig. 5 shows that the adsorption capacity of the ZSM-5 synthesized from

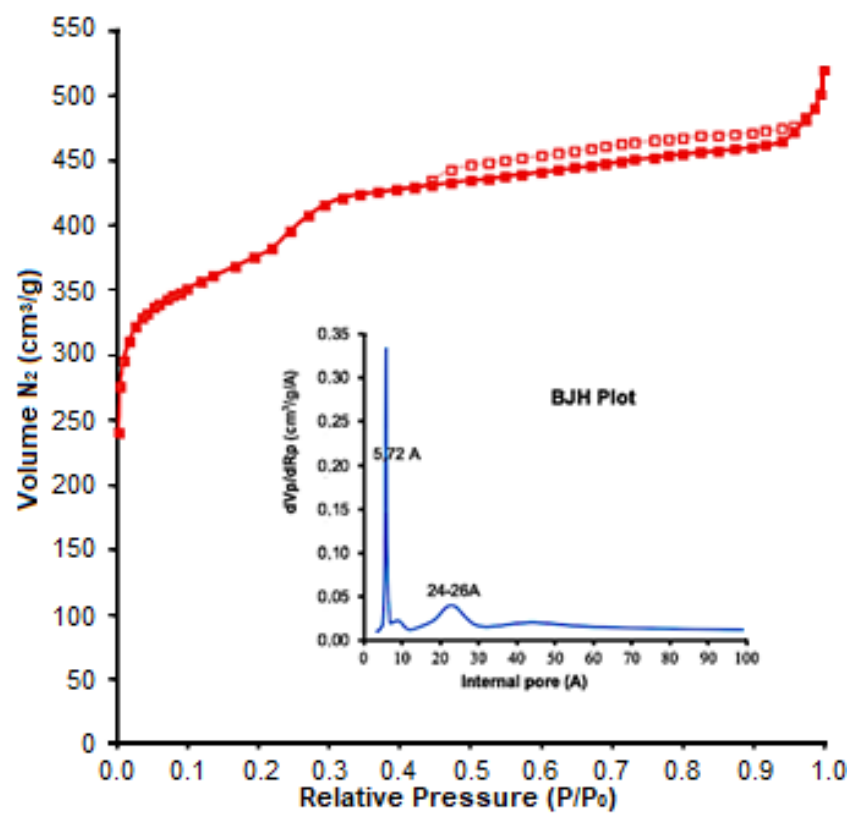

Fig 4. Nitrogen sorption equilibrium at $77 \mathrm{~K}$ of Synthesized ZSM-5 from Bangka kaolin adsorption studies 
Bangka kaolin increased along with the increase of initial concentrations. This result suggests that the removal of dyes depends on initial dyes concentration [18].

In general, the adsorption capacity of the ZSM-5 rises rapidly in the early time of the adsorption process, and it remains stable above 100 and $80 \mathrm{~min}$ of contact time, for both dyes. This phenomenon suggests that the adsorption has reached the equilibrium $[14,16,18]$. Apparently, the adsorption behavior for both dye solutions of $\mathrm{RB}$ and $\mathrm{MB}$ is not the same. The adsorption of $\mathrm{RB}$ is more irregular than the $\mathrm{MB}$ one. This is likely due to adsorption that takes place on the adsorbent ZSM-5 is less moderate on $\mathrm{RB}$ adsorbate than $\mathrm{MB}$ dye, which appears more regular and systematically. Of course, this is concerned with the structural difference of the 2 dyes, where MB molecule with a dimension of $5.9 \AA \times 13.8 \AA$ is smaller and straight whereas $\mathrm{RB}$ molecule with a dimension of $9.8 \AA \times 15.0 \AA$ are bulkier and would occupy larger areas [35-36]. This property leads to more irregular adsorption behavior of $\mathrm{RB}$ dyes due to similarity pore of ZSM-5 (24-26 ̊) with RB molecule dimension.

\section{Temperature Effect}

The effect of temperature on the adsorption of $\mathrm{RB}$ and MB dyes summarized Fig. 6. Based on those results, both dyes are rapidly adsorbed in the low temperature and decreased with increasing temperature. The increasing temperature can affect kinetics energy of adsorbate, which reduces the interactions between adsorbent-adsorbate. Although there is some difference among both dyes, $\mathrm{MB}$ dye is decreased more rapidly than RB. This fact correlated with the molecular size of MB that contributes to this phenomenon.

\section{Adsorption Isotherm}

Adsorption isotherm was calculated to understand the adsorption behavior of RB and MB dyes onto ZSM-5 from Bangka kaolin. By this analysis, the interaction between adsorbate and adsorbent could be examined. The analysis is carried out by fitting with four types of isotherm model, i.e., Langmuir, Freundlich, Temkin, and Dubinin-Radushkevich. The Langmuir model assumes that the adsorption occurs on a specified surface of homogeneous adsorbents. This adsorption could only form

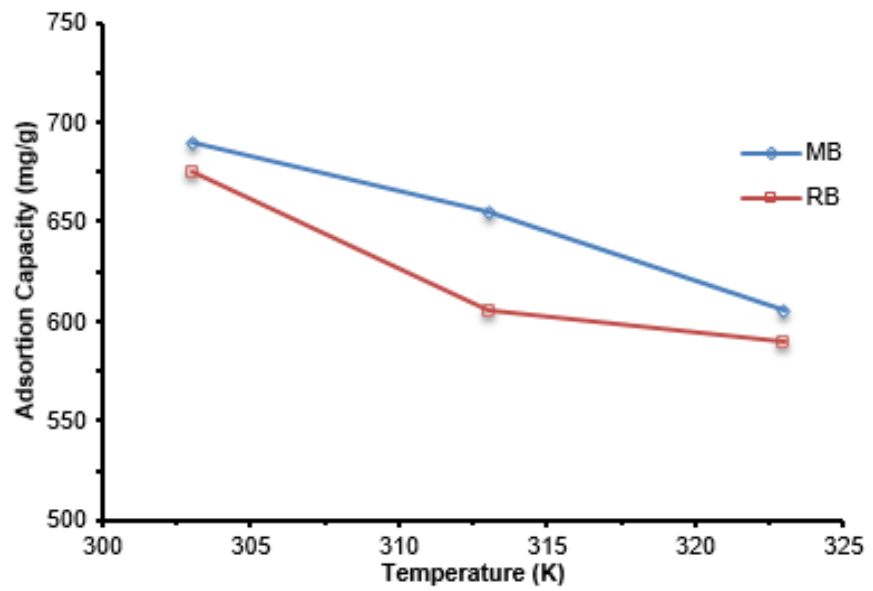

Fig 6. Effect of temperature on adsorption capacity

one layer of adsorbate in the surface of the adsorbent, meaning that each part of the surface in adsorbent could only hold one molecule or atom. This Langmuir model is presented in Eq. (2):

$\frac{\mathrm{C}_{\mathrm{e}}}{\mathrm{q}_{\mathrm{e}}}=\frac{1}{\mathrm{q}_{\mathrm{m}} \mathrm{b}}+\frac{\mathrm{C}_{\mathrm{e}}}{\mathrm{q}_{\mathrm{m}}}$

where $\mathrm{C}_{\mathrm{e}}\left(\mathrm{mg} \mathrm{L}^{-1}\right)$ is the equilibrium concentration, $\mathrm{q}_{\mathrm{e}}$ $\left(\mathrm{mg} \mathrm{g}^{-1}\right)$ is the amount of adsorbed adsorbate per unit mass of adsorbent, and $\mathrm{q}_{\mathrm{m}}$ is the adsorption capacity, and $\mathrm{b}$ is the rate of adsorption [37-40]. The Freundlich isotherm is used to represents the non-ideal heterogeneous behavior of the adsorption process. This model is presented in Eq. (3):

$\mathrm{Lnq}_{\mathrm{e}}=\mathrm{Lnk}_{\mathrm{f}}+\frac{1}{\mathrm{n}} \mathrm{LnC}_{\mathrm{e}}$

where $k_{\mathrm{f}}$ is the Freundlich constant $\left(\mathrm{mg} \mathrm{g}^{-1}\left(\mathrm{mg} \mathrm{L}^{-1}\right) \mathrm{n}\right)$, and $1 / \mathrm{n}$ is the heterogeneity factor ranged from 0 to 1 which is a characteristic of surface heterogeneity, becoming more homogeneous as its close to unity [3740].

The Temkin isotherm assumes that the adsorption heat of the adsorbate constantly decreases with adsorbent layer coverage rather than logarithmic due to the interaction of adsorbate and adsorbent. This model is presented in Eq. (4):

$\mathrm{q}_{\mathrm{e}}=\mathrm{B} \operatorname{Ln} \mathrm{A}+\mathrm{BLn}_{\mathrm{e}}$

where $\mathrm{B}$ is the constant related to the heat of sorption, and $\mathrm{A}\left(\mathrm{L} \mathrm{mg}^{-1}\right)$ is the Temkin equilibrium isotherm constant [38-40]. The Dubinin-Radushkevich isotherm model can be used to examine the porosity in relation to 
the free energy, E, and the characteristics of the adsorption process. This model is more general than the Langmuir model because it does not assume a homogeneous surface or constant adsorption potential. This isothermal equation is expressed in Eq. (5):

$\mathrm{Lnq}_{\mathrm{e}}=\mathrm{Lnq}_{\max }-\beta \varepsilon^{2}$

where $\mathrm{q}_{\mathrm{e}}$ and $\mathrm{q}_{\max }$ are defined above, $\mathrm{b}$ is the activity coefficient related to mean adsorption energy $\left(\mathrm{mol}^{2} \mathrm{~kJ}^{-2}\right)$, and $e$ is the Polanyi potential [38-39]. The calculation of all model is compiled in Table 1.

Based on the important parameter mentioned in Table 1 , the correlation coefficient $\left(\mathrm{R}^{2}\right)$ was used to determine the most suitable model for the adsorption of $\mathrm{RB}$ and MB dye onto ZSM-5. The results show that the Langmuir model possesses higher approximation to the value of one rather than the other models. The detailed trend is as follow: Langmuir $>$ Freundlich $>$ Temkin $>$ Dubinin-Radushkevich. This result suggests that the adsorption process of both dyes into adsorbents can be described better using the Langmuir model, which consider the adsorption to be monolayer rather than multi-layer adsorption $[16,18]$. This Langmuir adsorption is in good accordance with the isothermal adsorption type reported by several researchers. Vezensev et al. [25] reported in his findings that the adsorption of $\mathrm{MB}$ in bentonite-like clay and hydroxyapatite also followed the Langmuir model. The more recent findings reported by
Santosa et al. [26] also shows the same result. So did the result reported by Ding et al. [12]. This similarity is quite reasonable since the adsorbent material possessing active functional groups in its surface, such as activated carbon, zeolite material as well as pit soil humin could bind the dye molecules via those functional groups [26].

Another crucial finding based on this calculated provided in Table 1 is the adsorption capacity of the ZSM-5. The $\mathrm{Q}_{\mathrm{m}}$ values, which represents the maximum adsorption capacity for $\mathrm{RB}$ and $\mathrm{MB}$, are 97.08 and $128.21 \mathrm{mg} / \mathrm{g}$, respectively. This MB adsorption capacity is quite higher than other reported adsorbent materials such as hydroxyapatite with an adsorption capacity of $9.88 \mathrm{mg} / \mathrm{g}$ [25], mordenite $(37.362 \mathrm{mg} / \mathrm{g})$ [41], but it is lower than bentonite $(136.98 \mathrm{mg} / \mathrm{g})$ [25]. Turning to the rhodamine $\mathrm{B}$, the adsorption capacity in this works is higher than mordenite (3.61 mg/g) [23], montmorillonite $(42.19 \mathrm{mg} / \mathrm{g})$ [42] and bentonite $(98.62 \mathrm{mg} / \mathrm{g})$. However, the adsorption capacity of ZSM-5 in this works is much lower than activated carbon that has adsorption capacity up to $478.50 \mathrm{mg} / \mathrm{g}$ [12]. The difference in adsorption capacity is reasonable as the certain parameter in the adsorption process could influence the adsorbent performance. However, in adsorbent with the Langmuir model, it seems that the pore diameter and the functional groups that exist in the surface of the adsorbent play an important role in determining the adsorption capacity $[12,26]$.

Table 1. Parameters of several adsorption isotherm models for the adsorption of RB and MB on ZSM-5

\begin{tabular}{llcc}
\hline Mathematical Methods & Parameters & $\mathrm{RB}$ & $\mathrm{MB}$ \\
\hline Langmuir Isotherm & $\mathrm{R}^{2}$ & 0.9962 & 0.993 \\
& $\mathrm{~K}_{\mathrm{L}}$ & 0.007 & 0.009 \\
& $\mathrm{Q}_{\mathrm{m}}(\mathrm{mg} / \mathrm{g})$ & 128.21 & 97.08 \\
Freundlich Isotherm & $\mathrm{R}^{2}$ & 0.978 & 0.949 \\
& $\mathrm{~K}_{\mathrm{f}}$ & $4.6 \times 10^{6}$ & $13.6 \times 10^{4}$ \\
& $\mathrm{~N}$ & 0.54 & 0.48 \\
Temkin & & 0.0033 & 0.0036 \\
& $\mathrm{~B}(\mathrm{~mol} / \mathrm{KJ})$ & -776.02 & -788.91 \\
D-R & & 0.975 & 0.933 \\
& $\mathrm{q}_{\mathrm{m}}(\mathrm{mg} / \mathrm{g})$ & 161.95 & 137.15 \\
& $\mathrm{~B}$ & 0.0032 & 0.0035 \\
& $\mathrm{E}(\mathrm{KJ} / \mathrm{mol})$ & 12.500 & 11.952 \\
& $\mathrm{R}^{2}$ & 0.9228 & 0.855 \\
\hline
\end{tabular}

Ani Iryani et al. 


\section{Kinetic and Thermodynamic Studies}

The kinetics profile of $\mathrm{RB}$ and $\mathrm{MB}$ dyes adsorption on ZSM-5 adsorbent were conducted by batch method at an initial dye concentration of $50 \mathrm{mg} \mathrm{L}^{-1}$. The procedure of kinetics studies was similar to equilibration experiments with several preset intervals of sampling time. Three different kinetic models were used to investigate the kinetics studies, namely pseudo-firstorder, pseudo-second-order, and intraparticle diffusion models [38,43-45]. The results are shown in Table 2 . Based on the obtained coefficient of correlation from the adsorption of RB and MB dye onto ZSM-5, the pseudofirst-order model kinetics are more adequate than those obtained from the pseudo-second-order model. It can also be concluded that adsorption of $\mathrm{RB}$ and $\mathrm{MB}$ dye onto ZSM-5 has physically occurred because the pseudo-first-order-reaction was driven by one variable that is correlated with our result that the adsorption capacity depends on the concentration of adsorbate. The higher concentration of adsorbate increases the adsorption kinetics. Based on the intra-particle diffusion model, it seems that the intraparticle diffusion is not the rate limiting step as the straight line did not pass through the origin ( $\mathrm{C}$ value not equal to zero). This implies that other factor also plays a crucial role in adsorption such as film diffusion, adsorption of adsorbate on the interior surface of adsorbents or their combination [12,45]. The plot of the intra-particle kinetics model is shown in Fig. 7.

Table 2. Kinetic and thermodynamic parameters for the adsorption of RB and MB on ZSM-5

\begin{tabular}{clcc}
\hline Mathematical Methods & Parameters & $\mathrm{RB}$ & $\mathrm{MB}$ \\
\hline Pseudo-First-order kinetics & $\mathrm{R}^{2}$ & 0.9983 & 0.9952 \\
& $\mathrm{~K}_{1}$ & 0.0309 & 0.0274 \\
& $\mathrm{Q}_{\mathrm{e}}(\mathrm{mg} / \mathrm{g})$ & 789.66 & 977.01 \\
Pseudo-Second-order kinetics & $\mathrm{R}^{2}$ & 0.9762 & 0.9364 \\
& $\mathrm{~K}_{2}$ & $2.244 \times 10^{-5}$ & $7.199 \times 10^{-6}$ \\
& $\mathrm{Q}_{\mathrm{e}}(\mathrm{mg} / \mathrm{g})$ & 909.09 & 1250 \\
Intra-particle diffusion & $\mathrm{R}^{2}$ & 0.9024 & 0.9590 \\
& $\mathrm{k}_{\mathrm{id}}\left(\mathrm{g} / \mathrm{mg} / \mathrm{min}^{1 / 2}\right)$ & 58.668 & 69.085 \\
Thermodynamic study & $\mathrm{C}(\mathrm{mg} / \mathrm{g})$ & 24.706 & 101.84 \\
& $\mathrm{R}^{2}$ & 0.9648 & 0.8894 \\
& $\Delta \mathrm{H}^{\circ}(\mathrm{J} / \mathrm{mol})$ & -188.201 & -161.414 \\
& $\Delta \mathrm{S}^{\circ}(\mathrm{J} / \mathrm{mol} \mathrm{K})$ & 0.5940 & 0.517 \\
& $-\Delta \mathrm{G}^{\circ} \times 10^{2} \mathrm{~kJ} / \mathrm{mol}$ & & \\
& $303 \mathrm{~K}(\mathrm{~kJ} / \mathrm{mol})$ & -8.234 & 4.859 \\
& $313 \mathrm{~K}(\mathrm{~kJ} / \mathrm{mol})$ & -2.294 & -0.307 \\
& $323 \mathrm{~K}(\mathrm{~kJ} / \mathrm{mol})$ & -3.645 & -5.474031754 \\
\hline
\end{tabular}
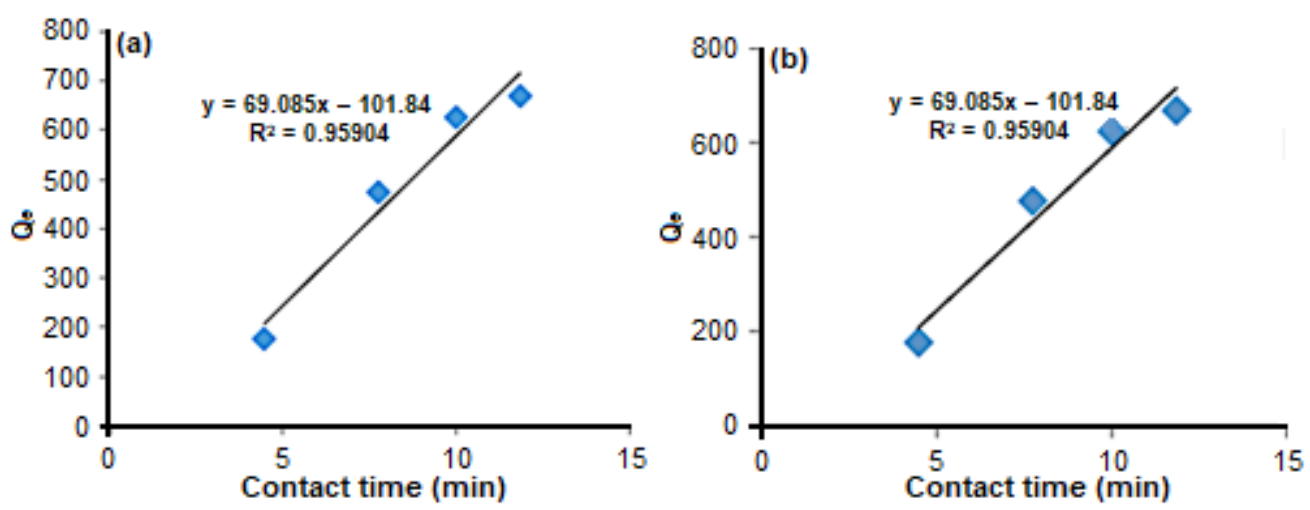

Fig 7. The kinetic plot of intra-particle diffusion model on (a) RB and (b) MB 
The effect of temperature in the adsorption process could be studied by analyzing the thermodynamic parameters. These thermodynamic parameters are presented in Table 2. The data shows that the adsorption of $\mathrm{RB}$ and $\mathrm{MB}$ is an exothermic reaction indicated by the negative value of $\Delta \mathrm{H}^{\circ}$. In the same way, the value of $\Delta \mathrm{G}^{\circ}$ is also found as a negative value indicating that this adsorption process could occur spontaneously in nature. This happened in all studied temperatures. However, those values are varied. The higher negative value of $\Delta \mathrm{G}^{\circ}$ indicates the energetically preferred process. Also, it seems that the $\Delta G^{\circ}$ decrease in line with the increase of temperature, suggesting that at a higher temperature, the driving force become lessen, thus lowering the adsorption uptake.

\section{- CONCLUSION}

In this paper, the ability of ZSM-5 from Bangka kaolin as an efficient adsorbent for $\mathrm{RB}$ and $\mathrm{MB}$ removal had been demonstrated. The fitting of the isothermal adsorption model revealed that the adsorption process follows the Langmuir model. The kinetic study revealed that the adsorption of both $\mathrm{RB}$ and $\mathrm{MB}$ follow the pseudofirst model indicating the intraparticle diffusion is not only the rate-limiting step but also is influenced by another factor such as film diffusion, adsorption of adsorbate on the interior surface of adsorbents. In addition, the thermodynamic studies indicate that all the adsorption process could occur spontaneously and exothermic. These findings confirm that ZSM-5 synthesized from Bangka kaolin could be promising as an adsorbent for RB and MB removal.

\section{- ACKNOWLEDGMENTS}

The authors acknowledge the Ministry of Research, Technology and Higher Education (KEMENRISTEKDIKTI) for financial support for this work through Acceleration of International Publication Program (P3I) grant.

\section{- REFERENCES}

[1] Rafatullah, M., Sulaiman, O., Hashim, R., and Ahmad, A., 2010, Adsorption of methylene blue on low-cost adsorbents: A review, J. Hazard. Mater., 177 (1-3), 70-80.

[2] Ip, A.W.M., Barford, J.P., and McKay, G., 2009, Reactive Black dye adsorption/desorption onto different adsorbents: Effect of salt, surface chemistry, pore size and surface area, J. Colloid Interface Sci., 337 (1), 32-38.

[3] Cardoso, N.F., Pinto, R.B., Lima, E.C., Calvete, T., Amavisca, C.V., Royer, B., Cunha, M.L., Fernandes, T.H.M., and Pinto, I.S., 2011, Removal of remazol black B textile dye from aqueous solution by adsorption, Desalination, 269 (1-3), 92-103.

[4] Gupta, V.K., Suhas, Ali, I., and Saini, V.K., 2004, Removal of rhodamine $B$, fast green, and methylene blue from wastewater using red mud, an aluminum industry waste, Ind. Eng. Chem. Res., 43 (7), 17401747.

[5] Rochkind, M., Pasternak, S., and Paz, Y., 2014, Using dyes for evaluating photocatalytic properties: a critical review, Molecules, 20 (1), 88-110.

[6] Inyinbor, A.A., Adekola, F.A., and Olatunji, G.A., 2015, Adsorption of Rhodamine B dye from aqueous solution on Irvingia gabonensis biomass: Kinetics and thermodynamics studies, S. Afr. J. Chem., 68, 115-125.

[7] Gillman, P.K., 2011, CNS toxicity involving methylene blue: The exemplar for understanding and predicting drug interactions that precipitate serotonin toxicity, J. Psychopharmacol., 25 (3), 429436.

[8] Abbasi, M., and Asl, N.R., 2008, Sonochemical degradation of Basic Blue 41 dye assisted by nanoTiO $\mathrm{T}_{2}$ and $\mathrm{H}_{2} \mathrm{O}_{2}$, J. Hazard. Mater., 153 (3), 942-947.

[9] Gupta, V.K., Jain, R., Mittal, A., Mathur, M., and Sikarwar, S., 2007, Photochemical degradation of the hazardous dye Safranin-T using $\mathrm{TiO}_{2}$ catalyst, $J$. Colloid Interface Sci., 309 (2), 464-469.

[10] Fan, L., Zhou, Y., Yang, W., Chen, G., and Yang, F., 2008, Electrochemical degradation of aqueous solution of Amaranth azo dye on ACF under potentiostatic model, Dyes Pigm., 76 (2), 440-446. 
[11] Sachdeva, S., and Kumar, A., 2009, Preparation of nanoporous composite carbon membrane for separation of rhodamine B dye, J. Membr. Sci., 329 (1-2), 2-10.

[12] Ding, L., Zou, B., Gao, W., Liu, Q., Wang, Z., Guo, Y., Wang, X., and Liu, Y., 2014, Adsorption of Rhodamine- $\mathrm{B}$ from aqueous solution using treated rice husk-based activated carbon, Colloids Surf., A, 446, 1-7.

[13] Malik, P., and Saha, S., 2003, Oxidation of direct dyes with hydrogen peroxide using ferrous ion as catalyst, Sep. Purif. Technol., 31 (3), 241-250.

[14] Brião, G.V., Jahn, S.L., Foletto, E.L., and Dotto, G.L., 2017, Adsorption of crystal violet dye onto a mesoporous ZSM-5 zeolite synthetized using chitin as template, J. Colloid Interface Sci., 508, 313-322.

[15] Heibati, B., Rodriguez-Couto, S., Amrane, A., Rafatullah, M., Hawari, A., and Al-Ghouti, M.A., 2014, Uptake of Reactive Black 5 by pumice and walnut activated carbon: Chemistry and adsorption mechanisms, J. Ind. Eng. Chem., 20 (5), 2939-2947.

[16] Hammed, A.K., Dewayanto, N., Du, D., Ab Rahim, M.H., and Nordin, M.R., 2016, Novel modified ZSM5 as an efficient adsorbent for methylene blue removal, J. Environ. Chem. Eng., 4 (3), 2607-2616.

[17] Lamia, M., Fatiha, D., Bouchekara, B., and Ayada, D., 2016, Adsorption of methyl green onto zeolite ZSM5 (pyrr.) in aqueous solution, Orient. J. Chem., 32 (1), 171-180.

[18] Nejad-Darzi, S.K.H., Samadi-Maybodi, A., and Ghobakhluo, M., 2013, Synthesis and characterization of modified ZSM-5 nanozeolite and their applications in adsorption of Acridine orange dye from aqueous solution, J. Porous Mater., 20 (4), 909-916.

[19] Jin, H., Ansari, M.B., Jeong, E.Y., and Park, S.E., 2012, Effect of mesoporosity on selective benzylation of aromatics with benzyl alcohol over mesoporous ZSM-5, J. Catal., 291, 55-62.

[20] Sabarish, R., and Unnikrishnan, G., 2017, Synthesis, characterization and catalytic activity of hierarchical ZSM-5 templated by carboxymethyl cellulose, Powder Technol., 320, 412-419.
[21] Yue, Y., Gu, L., Zhou, Y., Liu, H., Yuan, P., Zhu, H., Bai, Z., and Bao, X., 2017, Template-free synthesis and catalytic applications of microporous and hierarchical ZSM-5 zeolites from natural aluminosilicate minerals, Ind. Eng. Chem. Res., 56 (36), 10069-10077.

[22] Holmes, S.M., Khoo, S.H., and Kovo, A.S., 2011, The direct conversion of impure natural kaolin into pure zeolite catalysts, Green Chem., 13 (5), 11521154.

[23] Damiyine, B., Guenbour, A., and Boussen, R., 2017, Rhodamine $\mathrm{B}$ adsorption on natural and modified Moroccan clay with cetyltrimethylammonium bromide: Kinetics, equilibrium and thermodynamics, J. Mater. Environ. Sci., 12 (3), 860-871.

[24] Ngapa, Y.D., Sugiarti, S., and Abidin, Z., 2018, Hydrothermal transformation of natural zeolite from Ende-NTT and its application as adsorbent of cationic dye, Indones. J. Chem., 16 (2), 138-143.

[25] Vezentsev, A.I., Thuy, D.M., GoldovskayaPeristaya, L.F., and Glukhareva, N.A., 2018, Adsorption of methylene blue on the composite sorbent based on bentonite-like clay and hydroxyapatite, Indones. J. Chem., 18 (4), 733-741.

[26] Santosa, S.J., Kunarti, E.S., Aprilita, N.H., Wulandari, B., and Bawani, D.N., 2019, Sorption mechanism and performance of peat soil humin for methylene blue and p-nitrophenol, Indones. J. Chem., 19 (1), 198-210.

[27] Hartanto, D., Yuan, L.S., Sari, S.M., Sugiarso, D., Murwani, I.K., Ersam, T., Prasetyoko, D., and Nur, H., 2016, Can kaolin function as source of alumina in the synthesis of ZSM-5 without an organic template using a seeding technique?, Malays. J. Fundam. Appl. Sci., 12, 85-90.

[28] Vijayaraghavan, K., Padmesh, T., Palanivelu, K., and Velan, M., 2006, Biosorption of nickel(II) ions onto Sargassum wightii: Application of twoparameter and three-parameter isotherm models, $J$. Hazard. Mater., 133 (1-3), 304-308.

[29] Hamdaoui, O., and Naffrechoux, E., 2007, Modeling of adsorption isotherms of phenol and 
chlorophenols onto granular activated carbon Part I. Two-parameter models and equations allowing determination of thermodynamic parameters, $J$. Hazard. Mater., 147 (1-2), 381-394.

[30] Prasetyoko, D., Ayunanda, N., Fansuri, H., Hartanto, D., and Ramli, Z., 2012, Phase transformation of rice husk ash in the synthesis of ZSM-5 without organic template, J. Math. Fundam. Sci., 44 (3), 250-262.

[31] Mohamed, R.M., Fouad, O.A., Ismail, A.A., and Ibrahim, I.A., 2005, Influence of crystallization times on the synthesis of nanosized ZSM-5, Mater. Lett., 59 (27), 3441-3444.

[32] Armaroli, T., Simon, L.J., Digne, M., Montanari, T., Bevilacqua, M., Valtchev, V., Patarin, J., and Busca, G., 2006, Effects of crystal size and Si/Al ratio on the surface properties of H-ZSM-5 zeolites, Appl. Catal., A, 306, 78-84.

[33] Cychosz, K.A., and Thommes, M., 2018, Progress in the physisorption characterization of nanoporous gas storage materials, Engineering, 4 (4), 559-566.

[34] Wang, T., Lu, X., and Yan, Y., 2010, Synthesis, characterization and crystallization mechanism of SAPOs from natural kaolinite, Microporous Mesoporous Mater., 136 (1-3), 138-147.

[35] Canning, J., Huyang, G., Ma, M., Beavis, A., Bishop, D., Cook, K., McDonagh, A., Shi, D., Peng, G.D., and Crossley, M., 2014, Percolation diffusion into selfassembled mesoporous silica microfibres, Nanomaterials, 4, 157-174.

[36] Chen, C., Chen, Y., Lu, Z., Qian, M., Xie, H., and Tay, F.R., 2017, The effects of water on degradation of the zirconia-resin bond, J. Dent., 64, 23-29.

[37] Eren, Z., and Acar, F.N., 2006, Adsorption of Reactive Black 5 from an aqueous solution: Equilibrium and kinetic studies, Desalination, 194 (1-3), 1-10.
[38] Dada, A.O., Olalekan, A.P., Olatunya, A.M., and Dada, O., 2012, Langmuir, Freundlich, Temkin and Dubinin-Radushkevich isotherms studies of equilibrium sorption of $\mathrm{Zn}^{2+}$ unto phosphoric acid modified rice husk, IOSR J. Appl. Chem., 3 (1), 38-45.

[39] Foo, K.Y., and Hameed, B.H., 2010, Insights into the modeling of adsorption isotherm systems, Chem. Eng. J., 156 (1), 2-10.

[40] Allen, S.J., Mckay, G., and Porter, J.F., 2004, Adsorption isotherm models for basic dye adsorption by peat in single and binary component systems, J. Colloid Interface Sci., 280 (2), 322-333.

[41] Esmaeili, S., Zanjanchi, M.A., Golmojdeh, H., and Mizani, F., 2018, Increasing the adsorption capability of mordenite and Y zeolites via postsynthesis chemical/physical treatments in order to remove cationic dyes from polluted water, Water Environ. J., 0, 1-18.

[42] Selvam, P.P., Preethi, S., Basakaralingam, P., Thinakaran, N., Sivasamy, A., and Sivanesan, S., 2008, Removal of rhodamine B from aqueous solution by adsorption onto sodium montmorillonite, J. Hazard. Mater., 155 (1-2), 3944.

[43] Largitte, L., and Pasquier, R., 2016, A review of the kinetics adsorption models and their application to the adsorption of lead by an activated carbon, Chem. Eng. Res. Des., 109, 495-504.

[44] Ip, A.W.M., Barford, J.P., and McKay, G., 2010, A comparative study on the kinetics and mechanisms of removal of Reactive Black 5 by adsorption onto activated carbons and bone char, Chem. Eng. J., 157 (2-3), 434-442.

[45] Qiu, H., Lv, L., Pan, B., Zhang, Q., Zhang, W., and Zhang, Q., 2009, Critical review in adsorption kinetic models, J. Zhejiang Univ. Sci. A, 10 (5), 716-724. 